\title{
Exercise rehabilitation on home-dwelling patients with Alzheimer's disease - a randomized, controlled trial. Study protocol
}

\author{
Kaisu H Pitkala1*, Minna M Raivio ${ }^{1,2}$, Marja-Liisa Laakkonen ${ }^{1,3}$, Reijo S Tilvis ${ }^{4}$, Hannu Kautiainen ${ }^{5,6}$, \\ Timo E Strandberg ${ }^{7}$
}

\begin{abstract}
Background: Besides cognitive decline, Alzheimer's disease (AD) leads to physical disability, need for help and permanent institutional care. The trials investigating effects of exercise rehabilitation on physical functioning of home-dwelling older dementia patients are still scarce. The aim of this study is to investigate the effectiveness of intensive exercise rehabilitation lasting for one year on mobility and physical functioning of home-dwelling patients with AD.
\end{abstract}

Methods: During years 2008-2010, patients with AD $(n=210)$ living with their spousal caregiver in community are recruited using central $A D$ registers in Finland, and they are offered exercise rehabilitation lasting for one year. The patients are randomized into three arms: 1) tailored home-based exercise twice weekly 2) group-based exercise twice weekly in rehabilitation center 3) control group with usual care and information of exercise and nutrition. Main outcome measures will be Guralnik's mobility and balance tests and FIM-test to assess physical functioning. Secondary measures will be cognition, neuropsychiatric symptoms according to the Neuropsychiatric Inventory, caregivers' burden, depression and health-related quality of life (RAND-36). Data concerning admissions to institutional care and the use and costs of health and social services will be collected during a two year follow-up.

Discussion: To our knowledge this is the first large scale trial exploring whether home-dwelling patients with $A D$ will benefit from intense and long-lasting exercise rehabilitation in respect to their mobility and physical functioning. It will also provide data on cost-effectiveness of the intervention.

Trial registration: ACTRN12608000037303

\section{Background}

Dementia is the most important disease group leading to disability and requiring social and health care among older individuals [1]. The most prevalent of dementing illnesses (55-80\%) is Alzheimer's disease which leads to gradual and often steady decline of cognitive functioning, to various behavioural and psychological symptoms and physical disability [2]. Disabilities lead to loss of autonomy, require help and support as well as institutional care. Dementia with its consequences is also very expensive for the society [1].

\footnotetext{
* Correspondence: kaisu.pitkala@kolumbus.fi

'Unit of General Practice, Helsinki University Central Hospital, University of Helsinki, PO Box 20, 00014 University of Helsinki, Finland

Full list of author information is available at the end of the article
}

One pivotal problem in dementia leading to need for help and institutional care is decline in mobility. Locomotion gets stiff, walking decelerates and falls are common [3]. The stiffness and emerging disabilities makes caregivers' work demanding. Going outdoors, getting dressed and undressed as well as transfers from one place to another become challenging [1]. This process is accelerated by patient's progressive sarcopenia, weight loss and muscular weakness which impede body control and predisposes to falls [4].

Some earlier studies have suggested that physical exercise may be beneficial in dementia. Physical activity and regular exercise training may slow down cognitive decline [5,6], and it has positive effects on cognition among those with cognitive decline [7]. Exercise 
alleviates depression and reduces behavioural symptoms in dementia patients $[7,8]$. There are several controlled trials testing effectiveness of endurance or strength training among patients with dementia or in samples with a large proportion of patients with dementia. Most of the trials have a low number of participants and, therefore, low power to show effectiveness. In addition, many of the trials are not randomized. A meta-analysis of these trials showed a small but significant effect on strength and endurance outcomes [9]. Majority of these trials have been performed in nursing homes or in longterm care. One randomized study in a nursing home setting has shown that intensive, long-lasting exercise training may even improve physical functioning of Alzheimer's patients [10]. According to the trials showing effectiveness on physical functioning, the training program should be intensive, long-lasting and versatile.

We found only four clinical exercise trials targeted on home-dwelling patients with dementia [8,11-13]. Three of them were performed with very low number of patients $(\mathrm{N}=29-81)$ [11-13] and two of them did not show any effectiveness [11,12]. Teri's study [8] was targeted to improve behavioural symptoms in dementia. Thus, there are still only few rigorous randomized trials investigating the effectiveness of physical rehabilitation among home-dwelling patients with dementia. Although some studies have shown promising effects of exercise on physical functioning among institutionalized patients with dementia, there are no such studies among home-dwelling patients with Alzheimer's disease (AD).

We are testing intensive exercise training performed twice weekly either at patient's home or in a day centre and lasting for one year on patients Alzheimer's disease (AD). The primary aim of this study is to investigate the effects of exercise on AD patients' mobility and physical functioning. The secondary aims are to assess the effects of exercise interventions on patients' neuropsychiatric symptoms and cognition. We also investigate the effects of intervention on the use and costs of health care services, admissions of AD patients to permanent institutional care (cost-effectiveness), falls and mortality. The effects on the caregivers' quality of life will also be assessed.

\section{Methods}

\section{General design}

This is a multicenter, controlled intervention trial with a prospective, randomized design. The aim is to study the effects of two exercise interventions, one performed at AD patients' home for one hour twice a week, and another performed at rehabilitation day centres for four hours twice a week. The interventions will last for one year, and they are compared with usual care. The study has been approved by the Ethics Committee of the Helsinki University Central Hospital. Informed consent has been obtained from each patient and/or their spousal caregiver before any study procedure which are performed according to good clinical practice. An executive committee (KHP, TES, RST) is responsible for the planning, conduct and monitoring of the study.

\section{Participants}

The study was started in 2008 by posting a letter to a random sample of patients receiving reimbursement for AD medication according to the centralized Drug Imbursement Register of the Social Insurance Institution of Finland (Kela), and his/her spouse living at the same address. All these patients had undergone detailed diagnostic assessments before acquiring reimbursement for their AD medication (e.g. cognitive and neuropsychological tests, neuroimaging and laboratory tests). The outline of the exercise study was described, and they were invited to participate.

Besides AD and spouse requirement, the inclusion criteria are:

- living in the greater Helsinki area (Helsinki - Espoo

- Vantaa)

- age over 64 years

- no terminal disease, no severe hemiparesis

- independent mobility - with walking devices if needed

- frailty: at least one fall during last year, slowed walking speed, or weight loss during one year

All the spouses of the AD patients showing interest in participation are sent a questionnaire to confirm the fulfilment of the inclusion criteria and they are further interviewed via telephone about the frailty criteria, mobility and diseases. Those couples fulfilling inclusion criteria are invited for the first study nurse visit. At the beginning of the first visit the couples are given written and oral information of the study and they are asked to sign an informed consent. Both patients and their spousal caregivers give consent. In case of the AD patient's poor capability of judgement the spousal caregiver gives proxy's consent for both spouses.

\section{Study procedures}

The baseline study visit lasts about two hours and includes interview of both spouses' demographic data, diagnoses, medications used, and baseline use of health and social services. The diagnoses and medications are confirmed from medical records provided by the couples. Charlson comorbidity index is calculated to assess the severity and prognostic value of the participants' disease burden [14]. 
The AD patients are assessed by Clinical Dementia Rating Scale (CDR) [15], Minimental State Examination (MMSE) [16], verbal flow [17,18], clock drawing test [19], Mininutritional Assessment (MNA) [20], Neuropsychiatric Inventory (NPI) [21,22], Cornell depression test [23], mobility tests and balance tests [24], and the Functional Independence Measure (FIM) [25]. Patients' weight, blood pressure (with $10 \mathrm{~min}$ rest and recorded in a sitting position), heart rate and handgrip strength [26] are assessed on each visit. Falls and fractures are recorded with the aid of diaries kept by caregivers and recorded on each visit.

The spousal caregivers are assessed by the Zarit burden scale [27], Geriatric Depression Scale (GDS) [28], RAND36 $[29,30]$ and mobility and balance tests [24]. At six months the caregivers are asked to give feedback for the study and their satisfaction is assessed.

The couples are randomized in clusters of 30 . After assessing 30 couples with eligibility and frailty criteria confirmed and agreeing to consent the study, the randomization is performed. Couples are randomly allocated by means of computer-generated random numbers to three arms: to receive home rehabilitation, day care rehabilitation or to receive the usual care. The study nurse calls by telephone to a randomization staff member who has not seen the couples neither their clinical records. She assigns the next number from the computer and the group assignment to the patient.

Participating couples are assessed by two study nurses four times during the year: at baseline, and at 3, 6, and 12 months. In addition, those remaining in the community will be invited for a follow-up visit at 24 months. The study assessment procedures are described in table 1 . Use of health and social services, institutionalizations and death dates on both the patients and the caregivers will be retrieved from the central registers until two years from baseline measurements.

The flow chart of the study is described in figure 1.

\section{Intervention}

A total of 210 patients will be randomized in three groups (70 per each arm) as follows:

Table 1 Study assessment procedures and timetable.

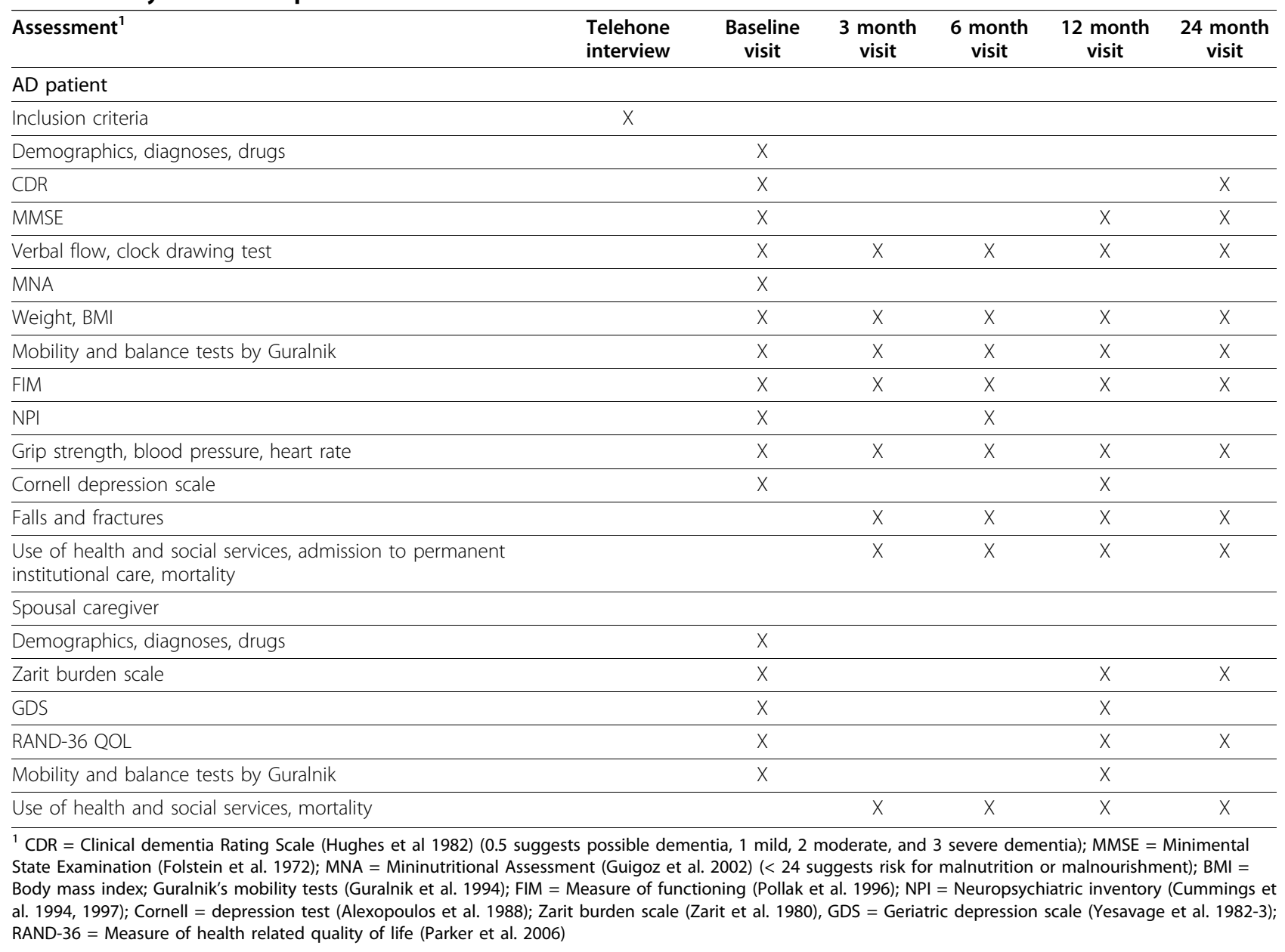




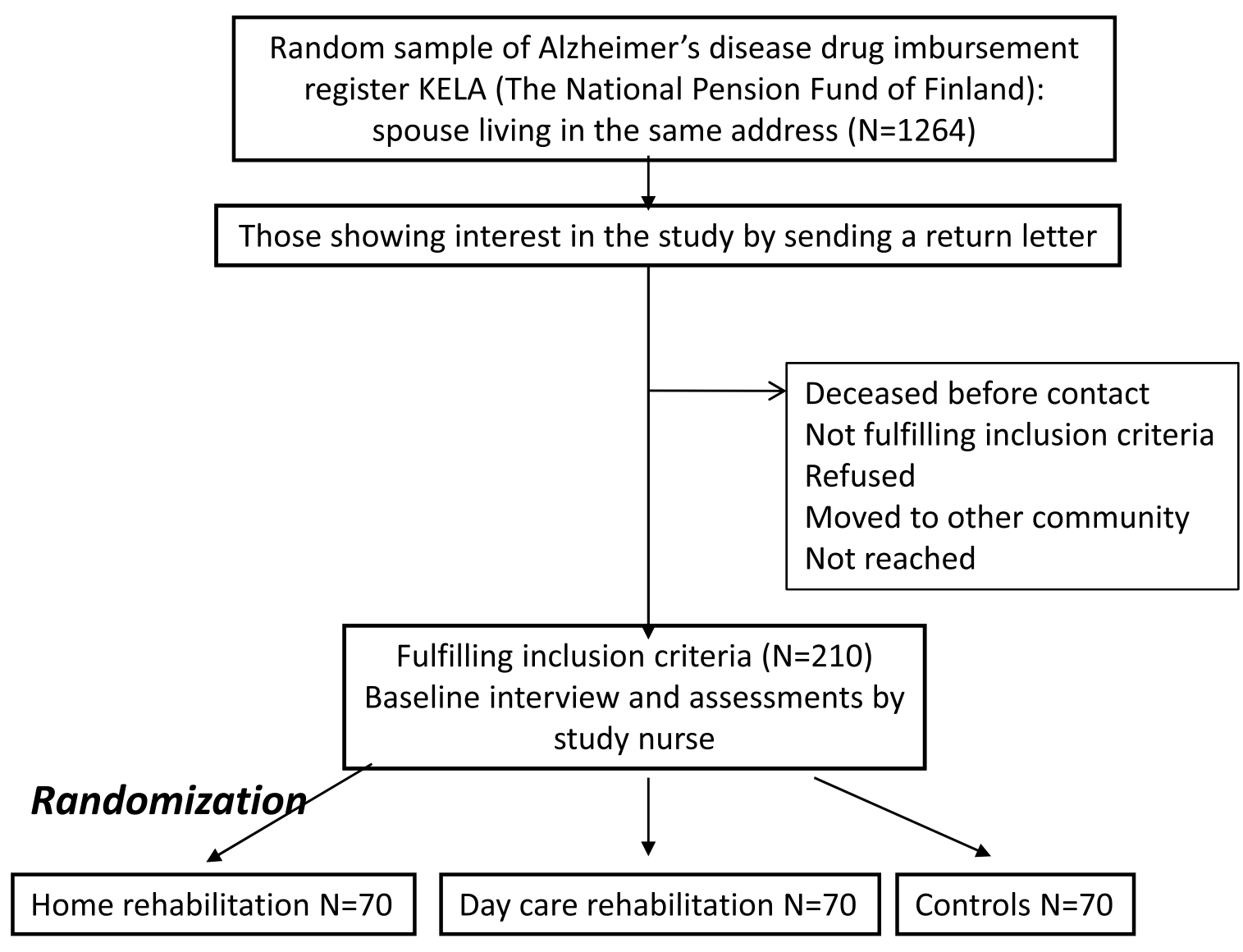

\section{reme (The National Pension Fund of Finland):}

spouse living in the same address $(N=1264)$

Those showing interest in the study by sending a return letter

Deceased before contact

Not fulfilling inclusion criteria

Refused

Moved to other community

Not reached

Fulfilling inclusion criteria $(\mathrm{N}=210)$

Baseline interview and assessments by

study nurse

3 months

Interview and assessments by

study nurse

Intervention

12 months

6 months

12 months

Interview and assessments by

study nurse

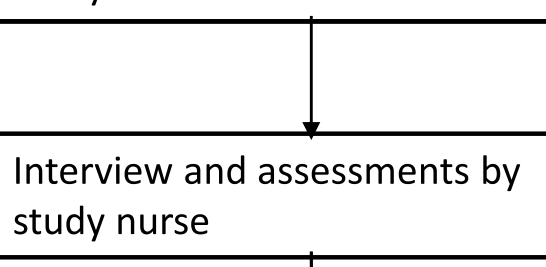

24 months

Interview and assessments by study nurse

Use of health and social services, costs, admissions

to permanent institutional care, mortality

Figure 1 Flow chart of the study. 


\section{Intervention}

A geriatrician performs comprehensive geriatric assessment prior the intervention and makes the rehabilitation plan including also nutritional care.

1. Home-based physical exercise and rehabilitation procedures (one hour twice a week for 12 months) are performed by physiotherapy professionals of an expert organization (Suomen Fysiogeriatria), with long-term experience of dementia exercise rehabilitation. Interventions are tailored according to the patient's and caregiver's needs (for example: training transfers, stair climbing, balance training, executive functioning or dual-tasking).

2. Day rehabilitation centre-based physical exercise and rehabilitation ( 4 hours twice a week for 12 months) is organized and performed by professionals of dementia physiotherapy at two day rehabilitation centres (with gym and experience) performing the day care rehabilitation. Intervention consists of endurance, balance, and strength training as well as dual task training and exercises directed to improve executive functioning. Taxi transportation and lunch are provided for participants during the intervention days.

The intervention is provided up to one year or until patient is admitted to permanent institutional care.

Patients randomized to the control group receive the usual care in normal health care system, but they are provided with oral and written advice on nutrition and exercise by the study organization.

As a nutritional advice, all patients receive advice to ensure a sufficient intake of energy and protein [4] and to take $20 \mu \mathrm{g}$ of vitamin D supplements per day [31].

\section{Outcome measurements}

Primary outcome measures are changes in patients' mobility assessed by the tests described by Guralnik et al [24] and in physical functioning according to the FIM measure [25].

Secondary outcome measures are changes in patients' cognition by verbal flow [17] and MMSE [16], neuropsychiatric symptoms by NPI [21,22] and Cornell [23], number of falls, and permanent institutionalizations and time spent at home. Changes in caregivers' satisfaction, burden by the Zarit burden scale [27], depression by the GDS [28], health-related quality of life by the RAND-36 $[29,30]$ will be measured as secondary outcomes.

Total mortality, use and costs of health and social care services of both spouses as well as cost-effectiveness of the intervention will be measured up to 24 months from the beginning of the baseline measurements.

\section{Statistical analyses}

Sample size was calculated based on the FIM measure [25]. With an estimated standard deviation 20, and type
I error 5\%, 80\% power, 63 patients would be needed in each group to show a 10-point difference between groups. With estimated $10 \%$ drop outs in each group about 70 patients are needed in each group. Data will be analyzed on intention-to-treat basis. Imputation method "the last observation carried forward" (LOCF) and "Worst-rank score"-principle will be used.

In these baseline findings, for the continuous variables, descriptive values were expressed by means with standard deviations (SD) and medians with range. For the variables with a normal (Gaussian) distribution, statistical comparisons between the groups are made by using an analysis of variance. If the variables have a non-normal distribution or ordinal level, statistical comparison between groups was made using the Kruskall-Wallis test. Measures with a discrete distribution were expressed as percentages (\%) and analysed by ChiSquare or Fischer's exact test when appropriate.

\section{Discussion}

This trial investigates the effects of intense, long-lasting physical exercise on home-dwelling patients with AD. It has two active intervention arms which are compared with usual care. One third of patients receive homebased tailored exercise twice a week one hour at the time for one year or until the patient is admitted to permanent institutional care. Another third of patients are receiving versatile exercise training including endurance, balance, and strength training as well as dual task training and exercises directed to improve executive functioning. This intervention is provided in day centers for four hours/day twice weekly for one year or until the patient is admitted to permanent institutional care.

There are several strengths in our study. All participants have an established diagnosis of AD because all are recruited from the drug register. This register requires definite diagnosis based on cognitive tests, disability, laboratory tests, and CT scan or MRI scan for the AD drug reimbursement. All participants suffer from frailty, and have therefore a need for exercise rehabilitation. Thus, the findings should be applicable in real life. The exercise training is intense and long-lasting, thus, reinforcing effectiveness of the intervention. The used resources and costs will be counted in detail.

However, there are also several challenges in this study. First, the population is old and frail with many comorbidities, and, thus, vulnerable to competing causes of complications and deaths. The second challenge relates to a sufficient difference to be attained between the groups with our intervention. Contamination of the control group is probably not a problem, because exercise rehabilitation is rarely available for dementia patients in Finland unless they are the Second World War veterans [32], in practice over 83 years of age in 
2008. Although the FIM has been developed to measure outcomes of rehabilitation and validated among very old patients [25], it is not very clear how the FIM measure will respond to change in functioning as a consequence of exercise intervention in patients with AD. It was also challenging to find suitable scales to measure change in cognition in this heterogeneous group consisting of all stages of dementia.

To our knowledge, this is the first large scale intervention trial exploring the effects of exercise on physical functioning among home-dwelling patients with dementia. This study will provide data whether exercise will have effect on physical functioning and use of health services among home-dwelling AD patients at risk for functional decline and institutional care.

\section{List of abbreviations}

AD: Alzheimer's disease; BMI: Body Mass Index; CDR: Clinical Dementia Rating scale; FIM: Functional Independence Measure; GDS: Geriatric Depression Scale; LOCF: Last observation carried forward; MMSE: Minimental State Examination; MNA: Mininutritional Assessment; NPI: Neuropsychiatric Inventory; QOL: Quality-of-Life; SD: Standard Deviation

\section{Acknowledgements}

This study is supported by the The Social Insurance Institution of Finland, The Central Union for the Welfare of the Aged, Sohlberg Foundation and King Gustaf V's and Queen Victoria's Foundation. The sponsors did not have any role in the design of study, neither in the collection, analysis or interpretation of data, nor in the writing the report.

\section{Author details}

'Unit of General Practice, Helsinki University Central Hospital, University of Helsinki, PO Box 20, 00014 University of Helsinki, Finland. ${ }^{2}$ The Social Insurance Institution of Finland, Helsinki, Finland. ${ }^{3}$ Helsinki City Health Center, Laakso Hospital, Lääkärikatu 8, 00250 Helsinki, Finland. ${ }^{4}$ Department of Internal Medicine and Geriatrics, Helsinki University Central Hospital, PO Box 340, 00029 HUS, Finland. ${ }^{5}$ Orton Orthopedic Hospital, Orton Foundation, Helsinki, Finland. 'Unit of Family Practice, Central Finland Central Hospital, Jyväskylä, Finland, Hämeentie 1, 44150 Äänekoski, Finland. 'Institute of Health Sciences/Geriatrics, University of Oulu, Oulu, Unit of General Practice, PO Box 5000, FIN-90014 Oulu, Finland.

\section{Authors' contributions}

Details of contributors: 1. Conception and design (KHP, TES, RST, MMR, MLL, $\mathrm{HK})$; 2. Acquisition of data, and statistical analysis and interpretation of data (KHP, TES, HK) 3. Drafting the article or revising it critically for important intellectual content (KHP, TES, RST, MMR, MLL, HK); 4. Final approval of the version to be submitted (KHP, TES, RST, MMR, MLL, HK). KHP is the guarantor.

\section{Competing interests}

Minna Raivio has been working part-time for the Social Insurance Institution of Finland. All the other authors declare that they have no competing interests.

Received: 21 April 2010 Accepted: 6 October 2010

Published: 6 October 2010

\section{References}

1. Alzheimer's Association: 2010 Alzheimer's disease facts and figures. Alzheimers Dement 2010, 6:158-94.

2. Knoptman D, Richie K, Polge C, Alafuzoff I, Soininen H: Alzheimer's disease. In Evidence-based dementia practice. Edited by: Qizilbash N, Schneider LS, Chui $\mathrm{H}$, Tariot P, Brodaty H, Kaye J, Erkinjuntti T. Oxford: Blackwell Publishing; 2002:228-59.
3. Cotter VT: The burden of dementia. Am J Manag Care 2007, 13(Suppl):193-197.

4. Gillette Guyonnet S, Abellan Van Kan G, Alix E, Andrieu S, Belmin J, Berrut G, Bonnefoy M, Brocker P, Constans T, Ferry M, Ghisolfi-Marque A, Girard L, Gonthier R, Guerin O, Hervy MP, Jouanny P, Laurain MC, Lechowski L, Nourhashemi F, Raynaud-Simon A, Ritz P, Roche J, Rolland Y, Salva T, Vellas B, International Academy on Nutrition and Aging Expert Group, IANA (International Academy on Nutrition and Aging) Expert Group: Weight loss and Alzheimer's disease. J Nutr Health Aging 2007, 11:38-48.

5. Kramer AF, Erickson Kl, Colcombe SJ: Exercise, cognition, and aging brain. J Appl Physiol 2006, 101:1237-1242.

6. Lautenschlager NT, Cox KL, Flicker L, Foster JK, van Bockxmeer FM, Xiao J, Greenop KR, Almeida OP: Effect of physical activity on cognitive function in older adults at risk for Alzheimer disease: a randomized trial. JAMA 2008, 300:1027-1037.

7. Heyn P, Abreu BC, Ottenbacher KJ: The effects of exercise training on elderly persons with cognitive impairment and dementia: a metaanalysis. Arch Phys Med Rehabil 2004, 85:1694-1704.

8. Teri L, Gibbons LE, McCurry SM, Logsdon RG, Buchner DM, Barlow WE, Kukull WA, LaCroix AZ, McCormick W, Larson EB: Exercise plus behavioral management in patients with Alzheimer disease: a randomized controlled trial. JAMA 2003, 290:2015-2022.

9. Heyn PC, Johnson KE, Kramer AF: Endurance and strength training outcomes on cognitively impaired and cognitively intact older adults: a meta-analysis. J Nutr Health Aging 2008, 12:401-409.

10. Rolland Y, Pillard F, Klapouszczak A, Reynish E, Thomas D, Andrieu S, Riviere $D$, Vellas $B$ : Exercise program for nursing home residents with Alzheimer's disease: a 1-year randomized, controlled trial. J Am Geriatr Soc 2007, 55:158-165.

11. Pomeroy VM, Warren CM, Honeycombe C, Briggs RS, Wilkinson DG, Pickering RM, Steiner A: Mobility and dementia: is physiotherapy treatment during respite care effective? Int I Geriatr Psychiatry 1999, 14:389-397.

12. Netz Y, Axelrad S, Argov E: Group physical activity for demented older adults feasibility and effectiveness. Clin Rehabil 2007, 21:977-986.

13. Kwak YS, Um SY, Son TG, Kim DJ: Effect of regular exercise on senile dementia patients. Int J Sports Med 2008, 29:471-474.

14. Charlson ME, Pompei P, Ales KL, MacKenzie CR: A new method of classifying prognostic comorbidity in longitudinal studies: development and validation. J Chronic Dis 1987, 40:373-383.

15. Hughes CP, Berg L, Danziger WL, Coben LA, Martin RL: A new clinical scale for the staging of dementia. Br J Psychiatry 1982, 140:566-572.

16. Folstein MF, Folstein SE, McHugh PR: "Mini-mental state". A practical method for grading the cognitive state of patients for the clinician. $J$ Psychiatr Res 1975, 12:189-198.

17. Morris JC, Heyman A, Mohs RC, Hughes JP, van Belle G, Fillenbaum G, Mellits ED, Clark C: The Consortium to Establish a Registry for Alzheimer's Disease (CERAD). Part I. Clinical and neuropsychological assessment of Alzheimer's disease. Neurology 1989, 39:1159-1165.

18. Welsh K, Butters N, Hughes J, Mohs R, Heyman A: Detection of abnormal memory decline in mild cases of Alzheimer's disease using CERAD neuropsychological measures. Arch Neurol 1991, 48:278-281.

19. Sunderland T, Hill JL, Mellow AM, Lawlor BA, Gundersheimer J, Newhouse PA, Grafman JH: Clock drawing in Alzheimer's disease. A novel measure of dementia severity. J Am Geriatr Soc 1989, 37:725-729.

20. Guigoz $Y$, Lauque $S$, Vellas BJ: Identifying the elderly at risk for malnutrition the Mini Nutritional Assessment. Clin Geriatr Med 2002, 18:737-757.

21. Cummings JL, Mega M, Gray K, Rosenberg-Thompson S, Carusi DA, Gornbein J: The Neuropsychiatric Inventory: comprehensive assessment of psychopathology in dementia. Neurology 1994, 44:2308-2014.

22. Cummings $\mathrm{JL}$ : The Neuropsychiatric Inventory: assessing psychopathology in dementia patients. Neurology 1997, 48(Suppl):10-16.

23. Alexopoulos GS, Abrams RC, Young RC, Shamoian CA: Cornell scale for depression in dementia. Biol Psychiatry 1988, 23:271-284.

24. Guralnik JM, Simonsick EM, Ferrucci L, Glynn RJ, Berkman LF, Blazer DG, Scherr PA, Wallace RB: A short physical performance battery assessing lower extremity function: association with self-reported disability and prediction of mortality and nursing home admission. J Gerontol 1994, 49: M85-94. 
25. Pollak N, Rheault W, Stoecker JL: Reliability and validity of the FIM for persons aged 80 years and above from a multilevel continuing care retirement community. Arch Phys Med Rehabil 1996, 77:1056-1061.

26. Rantanen T, Volpato S, Ferrucci L, Heikkinen E, Fried LP, Guralnik JM: Handgrip strength and cause-specific and toltal mortality in older disabled women: exploring mechanism. J Am Geriatr Soc 2003, 51:636-641.

27. Zarit SH, Reever KE, Bach-Peterson J: Relatives of the impaired elderly: correlates of feelings of burden. Gerontologist 1980, 20:649-655.

28. Yesavage JA, Brink TL, Rose TL, Lum O, Huang V, Adey M, Leirer VO: Development and validation of a geriatric depression screening scale: a preliminary report. J Psychiatr Res 1982, 17:37-49.

29. Aalto A, Aro A, Teperi J: RAND-36 as a measure of health-related quality of life. reliability, construct validity and reference values in the finnish genera population. Report No. 101. Helsinki: Stakes; 1999.

30. Parker SG, Bechinger-English D, Jagger C, Spiers N, Lindesay J: Factors affecting completion of the SF-36 in older people. Age Ageing 2006, 35:376-381.

31. Tang BM, Eslick GD, Nowson C, Smith C, Bensoussan A: Use of calcium or calcium in combination with vitamin $D$ supplementation to prevent fractures and bone loss in people aged 50 years and older: a metaanalysis. Lancet 2007, 370:657-666.

32. Raivio M, Eloniemi-Sulkava U, Laakkonen ML, Saarenheimo M, Pietilä M, Tilvis $R$, Pitkälä K: How do officially organized services meet the needs of elderly caregivers and their spouses with Alzheimer's disease? Am J Alzheimers Dis Other Demen 2007, 22:360-368.

doi:10.1186/1745-6215-11-92

Cite this article as: Pitkala et al.: Exercise rehabilitation on homedwelling patients with Alzheimer's disease - a randomized, controlled trial. Study protocol. Trials 2010 11:92.

\section{Submit your next manuscript to BioMed Central and take full advantage of:}

- Convenient online submission

- Thorough peer review

- No space constraints or color figure charges

- Immediate publication on acceptance

- Inclusion in PubMed, CAS, Scopus and Google Scholar

- Research which is freely available for redistribution

Submit your manuscript at www.biomedcentral.com/submit
Biomed Central 